\title{
'Enough is Enough': songs and messages about alcohol in remote Central Australia
}

\author{
GAVIN CARFOOT \\ Creative Industries Faculty, Queensland University of Technology, Kelvin Grove Campus, Queensland 4059, \\ Australia \\ E-mail: gavin.carfoot@qut.edu.au
}

\begin{abstract}
This article examines some of the ways in which Australia's First Peoples have responded to serious community health concerns about alcohol through the medium of popular music. The writing, performing and recording of popular songs about alcohol provide an important example of communityled responses to health issues, and the effectiveness of music in communicating stories and messages about alcohol has been recognised through various government-funded recording projects. This article describes some of these issues in remote Australian Aboriginal communities, exploring a number of complexities that arise through arts-based 'instrumentalist' approaches to social and health issues. It draws on the author's own experience and collaborative work with Aboriginal musicians in Tennant Creek, a remote town in Australia's Northern Territory.
\end{abstract}

\section{Introduction}

Following the highly controversial measures of the Northern Territory Emergency Response Bill (NTER) in 2007 - which involved a significant government-led intervention into public health and child safety issues in remote communities ( $\mathrm{D}^{\prime} \mathrm{Abbs}$ 2010, 2012) - research has illustrated how the mainstream media continues to reinforce negative, racist and deficit-based images of Indigenous health in Australia (Stoneham et al. 2014). Such deficit-based images have come to define much public discourse about Australian Indigenous health, focused in particular around the role of alcohol consumption and restriction in remote communities. Despite these deficit-based discourses, some Aboriginal and Torres Strait Islander communities have approached such public health issues in highly productive and asset-based ways, drawing on the knowledge and strength of Elders and communities in developing specific Indigenous-led responses. Outside mainstream media discourses about Indigenous health, Australian Indigenous musicians have used the medium of popular music to reflect on community issues and concerns in an assetbased manner which encourages positive social and cultural change. These community-based responses to alcohol through music provide the focus of this paper: as demonstrated in the songs that I have learnt and performed during my creative work in the remote community of Tennant Creek, musicians use popular music 
as an important response to the role of alcohol in the daily life of remote communities. ${ }^{1}$

\section{Australian Indigenous popular music}

While anthropological and ethnomusicological research into Australian Indigenous music once focused narrowly on what were considered 'traditional' cultural forms and practices, more recent critical research has engaged with the influence of global popular culture on Australian Indigenous musicians and musical culture: this includes work that has charted the origins and distinctive features of Australian Indigenous popular music (Breen 1989); the important influence and development of Aboriginal country music represented through the stories of its performers (Walker 2000); and a range of work has situated Australian Indigenous popular music in terms of its origins, expressions of place, identity, post-colonialism and cultural tourism (Dunbar-Hall and Gibson 2004). Corn (2010) has provided detailed readings of the social and cultural legacy of Mandawuy Yunupinu and Yothu Yindi for Yolnu culture in Northeast Arnehem Land, and the ways in which Yolnu beliefs, cultural practices, stories and traditions such as those of the yidaki (or didjeri$\mathrm{du}$ ) have been expressed through Western popular song forms (Corn and Gumbula 2003; Corn 2005). Barney has focused in particular on Aboriginal and Torres Strait Islander women's expressions in popular music, describing some key issues of intercultural collaboration in popular music that are evoked through the often-overlooked work of women musicians (Barney 2006, 2013). Mitchell has documented the importance of hip-hop in the expression of Australian Indigenous youth identities, noting how it is simultaneously derived from US-centric forms at the same time as it plays a role in distinctly regional cultural politics and social contexts (Mitchell 2001).

Much of this scholarly work has centred on the analysis of lyrical themes that highlight the importance of country, language and culture for Australian Indigenous peoples. Dunbar-Hall (1996) has described these kinds of themes in his sociolinguistic analysis of rock song lyrics, also identifying some specific examples of how Aboriginal popular music has been used as a strategy in government-funded public health education. This combination of popular music with a public health agenda can be described as 'instrumentalist' in approach, that is, an approach that justifies the public funding of music programmes as an 'instrument' for other forms of social change or benefit (Belfiore, 2002, p. 92). Such arts-based interventions have played a significant role in the Australian context, something that can be traced through various aspects of Indigenous visual arts and theatre (Gibson 2008; Glow and Johanson 2009). In particular, Dunbar-Hall describes a specific music-based initiative where recordings of songs by Aboriginal musicians were released in response to a public health report from the Anangu Pitjantjatjara lands. He notes the range of multilingual and 'kriol' forms used in the lyrics of these popular songs, providing examples of songs intended to spread messages about AIDS and alcohol abuse. As

${ }^{1}$ Following Ottosson, I tend to use the term 'Aboriginal' for mainland peoples including my friends and colleagues from Central Australia who identify with this term (Ottosson 2010, p. 297), as distinct from other more general terms such as Australian First Peoples or Australian Indigenous peoples, which are often used to refer collectively to the vast diversity of Aboriginal and Torres Strait Islander peoples in Australia. 
he writes about the song "Drangkinbala" (Drinking fella), by the group Blekbala Mujik, whose name is also in Kriol (Blackfella Music)', the song 'warns its listeners of the dangers of alcohol': 'yu shud libum jac grog en maindim bla yu femali, Ai Ai Ai Oh Oh Oh seibim bla yu laif from grog' (You should leave that grog and look after your family, Ai Ai Ai Oh Oh Oh save your life from grog) (Dunbar-Hall 2004, p. 46). In this case, Dunbar-Hall describes how Australian Aboriginal musicians' use of traditional languages and multilingual approaches in rock music lyrics reflects the ways in which languages are actually used in everyday community contexts, as well as the intentional use of hybrid language in popular song and as a means for communicating significant political, cultural and health-related issues.

Recent anthropological work by Ottosson has focused on the ways in which music performance and recording in the Central Australian town of Alice Springs (and surrounding country) is significant for Aboriginal men in a variety of ways, demonstrating various forms of 'whitefella' and 'blackfella' identities and masculinities that are expressed through making, performing and touring as popular musicians (Ottosson 2009). For many of these musicians, performing for non-Indigenous audiences functions as an important sign of success and a chance to 'talk-back' to a mainstream from which they are largely marginalised (Ottosson 2010). One of the common contexts for this is country music, a musical tradition through which Aboriginal men in Central Australia connect ancient and traditional knowledge and forms of masculine behaviour with the imagery of American country music, also in the context of non-Indigenous models of masculinity associated with colonial agricultural settler contexts and the history of Aboriginal stockmen or countrymen (Ottosson 2012). In this work, Ottosson describes the musical, social and cultural context of Central Australia as a complex intertwining of ancient and popular, where writing, recording and performing country, rock or reggae style songs and combining lyrics in the traditional language and in English are important ways for expressing agency in the face of significant historical and present-day challenges. Describing the prevalence of alcohol use in touring musicians' experiences, Ottosson writes about how 'many men take the opportunity to drink seriously when away from home, creating constant problems when band members cannot be found when it is time to perform, or performing poorly because they are drunk or hung-over' (Ottosson 2012, pp. 187-8). Ottosson describes not how these issues might be expressed in musical texts as such, but how the moral imaginary of so-called 'real' country music connects with the social and cultural ideas of Aboriginal musicians about the importance of responsible behaviour and respect for family. As Ottosson writes, Aboriginal musicians associated these values with American country music artists, and the Christian traditions circulated through the early missions of Central Australia:

This employment of a country music family imagery of morally responsible men who protect the innocence, and in particular the sexual innocence, of their women, is particularly effective in distinguishing blackfella real country musicians as men of higher moral worth. Versions of this imagery of belonging to a morally guided community/family are often evoked by the country musicians, and it is a common explanatory frame when they describe their passion for country music. (Ottosson 2012, p. 188)

The lived discourse of 'real' country music involves the evocation of truth and direct communication of the musicians' stories through song; musicians see this as an expression of their real lives (without inverted commas); their songs and stories are performed and understood as inextricable from their personal selves, their 
connection to culture and country. Read alongside Dunbar-Hall's sociolinguistic reading of Australian Aboriginal rock songs, Ottosson's work highlights the ways in which popular music and lyrics are drawn into deep and complex amalgams of culture and context, and it is in these terms - as a musician, songwriter and performer - that I have learnt about some aspects of Aboriginal people's experiences with music and alcohol as described below.

\section{Learning through musicking}

Over the past six years, I have collaborated with Indigenous and non-Indigenous musicians in Tennant Creek, a town in the vast Barkly Tableland region of Central Australia. Our work in Tennant Creek has been undertaken with Barkly Regional Arts (BRA), a multi-arts organisation which is also home to the Winanjjikari Music Centre (WMC) - a place for music making (literally 'singing for belonging' in the local Warumungu language) that includes recording studio facilities, rehearsal space and an extensive programme of training and community programmes run collaboratively by Aboriginal and non-Indigenous musicians and arts workers. BRA work on a range of community programmes that are often carried out in response to community health issues such as alcohol, highlighting 'the positive mental and physical health outcomes from community participation in the arts' (Burns 2015). In collaborative work with my wife Brydie-Leigh Bartleet, we have written about the service learning approach of this work, where we have taken groups of music students to WMC on immersive programmes designed to benefit the students, the community and the musicians of Tennant Creek in mutual ways (Bartleet and Carfoot 2013). We have written about the kinds of relationships and partnerships involved, how such partnerships are often defined through a move from 'transactional' to 'transformational' models (Bartleet et al. 2016a), and the ways in which concepts of citizenship can be critically read through arts-based approaches to service learning (Bartleet and Carfoot 2016). Our scholarly writing about this work is intimately informed and influenced by the complexities of our positions as non-Indigenous people working in a community setting where our relationships with Aboriginal people are central, and it is through critical positioning of ourselves that we have reflected on the kinds of transformational learning and deep intercultural perspectives that result from such work.

A significant contributor to this approach has been our engagement as collaborative musicians, where playing, jamming, songwriting and performing have served as the focal points for learning, relationship building and the development and expression of mutual respect. In this regard we have written about the ways in which songwriting and music making have encouraged approaches to intercultural learning which involve the triple lenses of facing each other through jamming and songwriting, facing others together through playing and performances, and facing ourselves through critical reflection on race and self in relation to our shared musical experiences (Bartleet et al. 2016b). Through the songs that we have listened to, been taught to play, performed and recorded, we have been presented with messages about alcohol from the multiple perspectives of our Aboriginal musicians, friends and colleagues. Through these types of experiences, we have been engaged in acts of musicking (Small 1998) that mean that - as researchers and students we have a relationship not only with popular music as cultural text or object, but 
as an embodied, performative experience where meaning is articulated in multiple ways. So when I think or write about the lyrics of songs that deal with the topic of alcohol, these songs represent deeply personal experiences, especially when the social and health impacts of alcohol are significant and inextricable from the lives of my collaborators, friends and colleagues. When these songs deal with issues about alcohol in the community or for individuals, they offer insights that are deeply personal at the same time as they are a way of expressing agency and selfdetermination. As non-Indigenous music student and musical collaborator Adam put it, reflecting on his burgeoning engagement with the bands and music of Tennant Creek:

... the focus is really on the lyrics. They write these real, direct lyrics which is - once you tune into them - because I'm not used to listening to music like that. So it took me a while to tune in to it. Then I started tuning into it and yeah, these real - just heartfelt lyrics and just really pure song writing. (Adam, personal interview)

In many cases, these deeply personal, embodied and musical experiences are formative for how I understand the connections between popular music and alcohol, but I hesitate to write about certain aspects, especially when they intersect with the personal lives of my collaborators. These factors deeply penetrate the ways in which we have encountered and understood the role of alcohol, smoking and other serious public health concerns of the community. These issues of approach and the types of apprehension that the researcher brings to a topic such as this are ultimately part of the dynamic and nuanced understanding of one's place as a non-Indigenous researcher, colleague, musical collaborator and friend working in a remote Aboriginal community. As we have spent time working in remote Central Australia, we have experienced many aspects of the impact that alcohol has had on the community, but even or especially because of this, it is clear that these are not my stories to tell: they are stories that have been shared most of all through the power and medium of popular song.

\section{Songs and stories of alcohol}

Stories in the mainstream media continue to reinforce negative, racist and deficitbased images of Indigenous health and alcohol use, something that is inextricable from the history of colonialism and its present-day legacies (Stoneham et al. 2014, p. 3; Ziersch et al. 2011; Larson et al. 2007). This scenario led Stoneham to emphasise counter-discourses of Indigenous health by creating storybooks in collaboration with the community, in order to "portray only positive stories describing how individuals or organisations have improved the health and wellbeing of their communities' (Stoneham et al. 2014, p. 8). A similar approach can be found in Wright's work, Grog War (1997, 2009), which describes the serious alcohol-related issues in Tennant Creek, but does so through the work of the Aboriginal-led Julalikari Council, who established a highly successful Night Patrol and other initiatives to address alcohol-related violence. In this way, Grog War tells a story about the positive outcomes that resulted from self-determination: Wright's work vividly describes the country, Elders and Aboriginal people of Tennant Creek as strong and courageous in the face of immeasurably complex social and cultural issues, offering an asset-based narrative account of the community's response to a serious public health concern. 
Our work with the community has been inspired by and through such positive forms of storytelling, drawing on asset-based approaches in collaboration with our musical collaborators. One of the musical events that we have contributed to is the annual BamFest performance, held as part of BRA's Desert Harmony Festival. The two weeks leading up to this event are a period in which we have jammed, learned new songs, written and recorded music and formed personal relationships with WMC musicians, bonding through our shared interest in music. This has often included the rapid learning of new repertoire for performance, and included extended periods of 'getting to know each other' through song. This facing of each other and ourselves through music is done through stories in song form, and these are stories that would otherwise be difficult to share or communicate outside this form of expression. While song themes about connection to country and culture are common and highly significant, songs that address one's individual life stories and personal challenges are also important. One young Aboriginal musician shared a hip-hop track about his problems with alcohol and violence, written while 'on holiday' in Alice Springs (a term used to refer to periods of incarceration). Referring to this and another song by his Aboriginal collaborator, non-Indigenous music student Adam commented:

I knew he'd been in jail and he's shown all the fingers he fought when he - by fighting and stuff when he was a young guy. The lyrics in the song were ... You make your own choices in life and you're in control of your own - yeah, the lyrical - the lyrics. It was just delivered in this ... real direct, straight talking way and yeah, got tears in my eyes. I'm actually getting tingles now just thinking about it. (Adam, personal interview)

Some of the most rewarding and moving experiences of performing with Aboriginal musicians have been with band the Tableland Drifters: through playing, writing and learning songs with this band we have learnt about many of the perspectives and challenges of life in remote communities through the lens of song. It has often been through the guidance, generosity and good humour of Elders that we have come to know some of the stories of their country, including songs about drinking as part of daily life in a remote community. The fact that some of these musicians and Elders are no longer with us adds deep personal sadness and particular weight to the messages in these songs (in addition to the fact that their names cannot be mentioned due to cultural protocols). In the song 'Enough is Enough' by the Tableland Drifters - produced as a form of public education with non-Indigenous collaborator and producer Jeff McLaughlin - the lead singer tells a story that aims to educate community members about the dangers of drinking and driving: 'When you get behind the wheel drive home safely ... After the party be careful on the way, don't be a fool, temptation and alcohol ... Enough is enough, enough is enough.' This song demonstrates the way that alcohol as a community health issue is intertwined with multiple perspectives including that of road safety, and an example of an instrumentalist approach that has provided positive and professional work for Aboriginal musicians as community leaders and Elders. In another song, 'Pocketful of Money', a now-deceased musician of importance in the Tennant Creek community sings a story about payday - the day of the week in which welfare payments are distributed to community members. Written and recorded without a particular funding programme or public health agenda in mind, this song tells a story about the effect of payday, something that Aboriginal Elders and leaders in 
some communities have addressed independently of the NTER. In typical desert reggae style, the song tells the story:

Standing by the roadside

Trying to catch a ride

You've been hangin' round

Just to get to town

Chorus

With a pocketful of money

You want to spend it all

With nothing else to worry

You wanna drink 'till you fall

You finally get to town

And grog's on your mind

You go straight to the pub

And you drink it all up

Repeat chorus

The next day you are broke

And no money for your smoke

No ride to your home

And your family's home alone

Repeat chorus

So think about yourself

When your families need your help

Be a good sport

And give them your support

Repeat chorus

In this song - again mixed and mastered by non-Indigenous musical colleague and friend Jeff McLaughlin - we have an example of a respected musician taking this theme not in a prescribed way, but as a reflection on their own community, expressed through the distance of second-person narrative. The song speaks to the ideas of respecting family that Ottosson notes in her studies of 'real country', and narrates a story about alcohol intended to resonate with the everyday experiences of many community members. These examples ultimately share much in common with the types of popular songs about alcohol that Dunbar-Hall described in the example of music released following a public health report from the Anangu Pitjantjatjara lands (Dunbar-Hall 2004), and as such they demonstrate a continuation of this practice of addressing public health concerns through popular music. However, other songs display lyrical themes where drinking is not positioned directly in relation to the acknowledged public health issues, but rather in ways that acknowledge the image of alcohol as a means of celebration rather than an inherent problem in itself. The song 'The Rock' by Band Nomadic presents this in its final repeated lines - 'and now we're drinking to our Uluru' - referring to the story of Aboriginal land rights claims over the famous Central Australian site: 'In 1985 the Rock has come alive, / An evening in October the rock was handed over ... / Our friends and our supporters we say thank you, / For helping keep our heritage alive ... / And now we're drinking to our Uluru ...'. This use of drinking as a symbol of celebration reminds us of the complexities involved when examining popular music and alcohol in these settings. 
Images of alcohol in popular music range from these kinds of celebratory symbols, through to symbols of serious and life-threatening public health issues. While many songs reflect on the seriousness of alcohol in a community like Tennant Creek, it is also the case the songs present varied images of alcohol across of the spectrum from the banal, to the celebratory, to the critical.

\section{Conclusion}

The story about popular music and alcohol in Tennant Creek is not mine to tell. Rather, it is something that I try to understand and follow through the experiences, songs and stories that I encounter in my collaborative relationships with Aboriginal musicians, community members, collaborators and friends, along with the other non-Indigenous musicians and arts workers with whom I collaborate in the community. The reality of the public health situation in remote Aboriginal communities is something that is receiving increasing attention from scholars in the wake of the NTER, and previous approaches that have foregrounded supposedly abstract notions of 'culture' have been criticised for not being able to demonstrate an actual contribution to the improvement of people's lives: as argued in well-known critical work by Sutton, when faced with the gravity of health issues experienced by Australia's First Peoples one can no longer defer to political and scholarly agendas and approaches that have ultimately done little to improve the actual lives of marginalised peoples (Sutton 2009; Altman and Hinkson 2010). Following this kind of critique, it may seem difficult if not impossible to justify the role of arts-based instrumentalism in effecting change. Nonetheless, popular music provides an important means of reflecting on the role of alcohol in the community for Aboriginal musicians. In this sense, songs about alcohol sit alongside other recurring themes such as connection to country, maintenance of language, the importance of culture and selfdetermination: songs about alcohol are but one part of a complex popular music repertoire where song forms and lyrical themes are inextricable from the realities of everyday life and culture for Aboriginal musicians in Central Australia. These stories provide important counter-currents to any temptation we might have to think about the relationship between music and alcohol in trivial or flippant ways. In remote Aboriginal communities, alcohol can be seen as a locus for the ongoing and devastating effects of colonialism, and it is through the lens of popular musical forms that I have learned at least a small amount about the strength and courage with which Aboriginal musicians and communities approach this issue.

\section{References}

Altman, J.C., and Hinkson, M. 2010. Culture Crisis: Anthropology and Politics in Aboriginal Australia (Sydney, NSW, University of New South Wales Press)

Barney, K. 2006. "Women singing up big": the growth of contemporary music recordings by indigenous Australian women artists', Australian Aboriginal Studies, 1, pp. 44-56

Barney, K. 2013. 'Musical entanglements at the contact zone: exploring Indigenous and non-Indigenous Australian collaborations through contemporary music', in Communities, Places, Ecologies: Proceedings of the 2013 IASPM-ANZ Conference, ed. J. O'Regan and T. Wren (Brisbane, International Association for the Study of Popular Music), pp. 1-12

Bartleet, B.L., and Carfoot, G. 2013. 'Desert harmony: stories of collaboration between Indigenous musicians and university students', The International Education Journal: Comparative Perspectives. Special Issue: Global 21st 
Century Professionals: Developing capability to work with Indigenous and other Traditionally-Oriented Peoples, 12/ 1, pp. 180-96

Bartleet, B.-L., and Carfoot, G. 2016 (in press). 'Arts-based service learning with Indigenous communities: engendering artistic citizenship', in Oxford Handbook of Artistic Citizenship, ed. D. Elliott and M. Silverman (Oxford, Oxford University Press)

Bartleet, B.-L., Carfoot, G., and Murn, A. 2016a. 'Exploring partnerships between Australian Aboriginal communities, community arts organizations and universities', in Arts-Based Service Learning with First Peoples: Towards Respectful and Mutually Beneficial Educational Practices, ed. B.-L. Bartleet, D. Bennett, A. Power and N. Sunderland (New York, Springer), pp. 31-49

Bartleet, B.-L., Sunderland, N., and Carfoot, G. 2016b (in press). 'Enhancing intercultural engagement through service learning and music making with indigenous communities in Australia', Research Studies in Music Education

Belfiore, E. 2002. 'Art as a means of alleviating social exclusion: does it really work? A critique of instrumental cultural policies and social impact studies in the UK', International Journal of Cultural Policy 8/1, pp. 91-106

Breen, M. (ed.). 1989. Our Place, Our Music: Aboriginal Music: Australian Popular Music in Perspective (Canberra, ACT, Aboriginal Studies Press)

Burns, K. 2015. Delivering Multi Arts in the Barkly Region: 13th National Rural Health Conference, Barkly Regional Arts blog. http://barklyarts.com.au/13th-national-rural-health-conference-2/ (accessed 1 September 2015)

Corn, A. 2005. 'When the waters will be one: hereditary performance traditions and the yolpu re-invention of post-barunga intercultural discourses', Journal of Australian Studies, 28/84, p. 23

Corn, A. 2010. 'Land, song, constitution: exploring expressions of ancestral agency, intercultural diplomacy and family legacy in the music of yothu yindi with Mandawuy Yunupingu', Popular Music, 29/1, p. 81

Corn, A., and Gumbula, N. 2003. "'djiliwirri ganha dharranhana, wana limurrungu": the creative foundations of a yolnu popular song', Australasian Music Research, 7, pp. 55-66

D'Abbs, P. 2010. 'Controlling "rivers of grog": the challenge of alcohol problems in Australian Indigenous communities', Contemporary Drug Problems 37/3, p. 499

D'Abbs, P. 2012. 'Problematizing alcohol through the eyes of the Other: alcohol policy and Aboriginal drinking in the Northern Territory, Australia', Contemporary Drug Problems, 39/3, pp. 371-96

Dunbar-Hall, P. 1996. 'Rock songs as messages: issues of health and lifestyle in central Australian aboriginal communities', Popular Music and Society, 20/2, 43-67

Dunbar-Hall, P. 2004. "Alive and deadly": a sociolinguistic reading of rock songs by Australian Aboriginal musicians', Popular Music and Society, 27/1, pp. 41-8

Dunbar-Hall, P., and Gibson, C. 2004. Deadly Sounds, Deadly Places: Contemporary Aboriginal Music in Australia (Kensington, NSW, UNSW Press)

Gibson, L. 2008. 'In defence of instrumentality', Cultural Trends, 17/4, pp. 247-57

Glow, H., and Johanson, K. 2009. 'Instrumentalism and the "helping" discourse: Australian Indigenous performing arts and policy', International Journal of Cultural Policy, 15/3, pp. 315-28

Larson, A., Gillies, M., Howard, P., and Coffin, J. 2007. 'It's enough to make you sick: the impact of racism on the health of Aboriginal Australians', Australian and New Zealand Journal of Public Health, 31/4, pp. 322-9

Mitchell, T. (ed.). 2001. Global Noise: Rap and Hip-hop Outside the USA (Middletown, CT, Wesleyan University Press)

Ottosson, Å. 2009. 'Playing with others and selves: Australian aboriginal desert musicians on tour', Asia Pacific Journal of Anthropology, 10/2, pp. 98-114

Ottosson, A. 2010. 'Aboriginal music and passion: interculturality and difference in Australian desert towns', Ethnos, 75/3, pp. 275-300

Ottosson, A. 2012. 'The intercultural crafting of real Aboriginal country and manhood in Central Australia', Australian Journal of Anthropology, 23/2, pp. 179-96

Small, C. 1998. Musicking: The Meanings of Performing and Listening (Hanover, NH, University Press of New England)

Stoneham, M.J., Goodman, J., and Daube, M. 2014. 'The portrayal of Indigenous health in selected Australian media', International Indigenous Policy Journal, 5/1, pp. 1-13

Sutton, P. 2009. The Politics of Suffering: Indigenous Australia and the End of the Liberal Consensus (Melbourne, VIC, Melbourne University Press)

Walker, C. 2000. Buried Country: The Story of Aboriginal Country Music (Annandale, NSW, Pluto Press)

Wright, A. 2009. Grog War (Broome, WA, Magabala Books)

Ziersch, M.A., Gallaher, G., Baum, F., and Bentley, M. 2011. 'Responding to racism: insights on how racism can damage health from an urban study of Australian Aboriginal people', Social Science and Medicine, 73, pp. 1045-53 